\title{
PENGARUH MOTIVASI DAN DISIPLIN KERJA TERHADAP KINERJA KARYAWAN PADA PT. GRACIA MITRA SELARAS PUSAT PANTAI INDAH KAPUK JAKARTA UTARA
}

\author{
${ }^{1 *}$ Kemas Vivi Andayani, ${ }^{2 J e n i}$ Ariska \\ Universitas Pamulang, Tangerang Selatan, Banten, Indonesia \\ *dosen01342@unpam.ac.id
}

\begin{abstract}
Abstrak
Penelitian ini bertujuan untuk mengetahui seberapa besar pengaruh motivasi dan disiplin kerja terhadap kinerja karyawan pada PT. Gracia Mitra Selaras Pusat Pantai Indah Kapuk Jakarta Utara.Metode penelitian yang digunakan dalam penelitian ini adalah metode kuantitatif. Data penelitian dikumpulkan dengan metode penyebaran kuesioner, pengambilan sampel menggunakan analisis data antara lain: Uji Validitas, Uji Reabilitas, Uji Asumsi Klasik, Korelasi Berganda, Analisis Regresi Linear Sederhana, Analisis Regresi Linear Berganda, Uji Hipotesis. Berdasarkan hasil perhitungan analisis regresi linear diperoleh persamaan $Y=5,129+0,328(X 1)+0,492(X 2)$ dengan nilai koefisien determinasi (R Square) sebesar 0,246 atau 24,6\% membuktikan bahwa variabel motivasi dan disiplin kerja memberikan kontribusi atau pengaruh sebesar $24,6 \%$ terhadap kinerja karyawan sedangkan sisanya sebesar $75,4 \%$ dipengaruhi oleh faktor lain yang tidak diteliti pada penelitian ini. Dan berdasarkan uji hipotesis dengan menggunakan uji t (parsial) antara variabel Motivasi (X1) dengan variabel Kinerja $(\mathrm{Y})$ hasil $\mathrm{t}$ hitung $>\mathrm{t}$ tabel $(3,660>1,985)$ menunjukan bahwa motivasi berpengaruh terhadap kinerja karyawan, sedangkan hasil uji $t$ antara variabel disiplin kerja (X2) dengan variabel kinerja $(\mathrm{Y})$ hasil $\mathrm{t}$ hitung $>\mathrm{t}$ tabel $(4,891>1,985)$ yang artinya disiplin kerja berpengaruh terhadap kinerja karyawan. Berdasarkan uji $\mathrm{f}$ antara variabel motivasi dan disiplin kerja terhadap kinerja karyawan, hasil hitung $\mathrm{f}$ hitung $>\mathrm{ftabel}=17,965>3,10$ dengan tingkat signifikansi 0,000 < 0,05. Maka Ho di tolak dan Ha diterima yang menyatakan terdapat pengaruh yang signifikan secara simultan (bersama) antara pengaruh motivasi dan disiplin kerja terhadap kinerja karyawan pada PT. Gracia Mitra Selaras Pusat Pantai Indah Kapuk Jakarta Utara.
\end{abstract}

Kata Kunci: Motivasi, Disiplin Kerja, Kinerja

\begin{abstract}
This study aims to determine how much influence motivation and work discipline on employee performance at PT. Gracia Mitra Selaras Pusat Pantai Indah Kapuk, North Jakarta. The research method used in this study is a quantitative method. The research data was collected by using a questionnaire method, sampling using data analysis including: Validity Test, Reliability Test, Classical Assumption Test, Multiple Correlation, Simple Linear Regression Analysis, Multiple Linear Regression Analysis, Hypothesis Testing. Based on the results of linear regression analysis calculations, the equation $Y=5.129+0.328(\mathrm{X} 1)+0.492(\mathrm{X} 2)$ with a coefficient of determination (R Square) of 0.246 or $24.6 \%$ proves that the motivation and work discipline variables contribute or influence $24,6 \%$ of employee performance while the remaining $75.4 \%$ is influenced by other factors not examined in this study. And based on hypothesis testing using $t$ test (partial) between motivation variable (X1) and performance variable $(Y)$ the results of t count $>t$ table $(3.660>1.985)$ show that motivation affects employee performance, while the results of $t$ test between work discipline variables (X2) with the performance variable $(Y)$ the results of $t$ count $>t$ table $(4,891>1,985)$ which means that work discipline has an effect on employee performance. Based on the f test between the variables of motivation and work discipline on employee performance, the results of the calculated $f$ count $>$ ftable $=17.965>3.10$ with a significance level of $0.000<0.05$. So Ho is rejected and Ha is accepted which states that there is a simultaneous (joint) significant effect between the influence of motivation and work discipline on employee performance at PT. Gracia Mitra Selaras Pantai Indah Kapuk Center, North Jakarta.
\end{abstract}

Keywords: Motivation, Work Discipline, Performance 


\section{PENDAHULUAN}

Untuk mencapai kemajuan perusahaan, faktor manusia merupakan salah satu variabel yang sangat penting. Karena berhasil atau tidaknya suatu perusahaan sebagian besar ditentukan oleh perilaku-perilaku manusia yang menjalankan pekerjaan. Pemberian motivasi kerja baik eksternal maupun internal yang semakin baik dapat menjadi dorongan bagi karyawan agar bekerja semakin produktif. Dengan kinerja yang baik maka pengeluaran beban karyawan per unit semakin kecil, selain itu perusahaan dapat memberikan kesempatan kepada setiap karyawan untuk berkembang,

Pada upaya memupuk motivasi kerja ke arah peningkatan kerja yang lebih tinggi, karena dengan pemenuhan kebutuhan yang sesuai dengan yang di harapkan para karyawan terutama imbalan finansial berupa remunerasi, serta bonus atas kinerja mereka, adanya pemenuhan kebutuhan yang sesuai tersebut di harapkan para karyawan dapat fokus terhadap pekejaan yang akan di lakukannya.

PT. Gracia Mitra Selaras merupakan perusahaan yang bergerak di bidang retail supermarket bertaraf internasional yang beroperasi dengan nama Market City, perusahaan ini sangat mengedepankan kualitas produk dan service excellent. Lebih dari produk makanan dan barang kebutuhan hidup lainnya, tersedia dengan harga bersaing untuk memenuhi kebutuhan sehari hari. Hingga kini

Tabel 1. Kompensasi PT.Graca Mitra Selaras Pusat Pantai Indah Kapuk Jakarta Utara

\begin{tabular}{|c|c|c|c|}
\hline \multirow{2}{*}{ Tahun } & \multicolumn{2}{|c|}{ Kompensasi } & \multirow{2}{*}{ UMK DKI Jakarta } \\
\cline { 2 - 4 } & Gaji & Bonus & \\
\hline 2017 & $\mathrm{Rp} 3.355 .000$ & $\mathrm{Rp} 2.700 .000$ & $\mathrm{Rp} 3.355 .000$ \\
\hline 2018 & $\mathrm{Rp} 3.648 .035$ & $\mathrm{Rp} 1.300 .000$ & Rp3.648.035 \\
\hline 2019 & $\mathrm{Rp} 3.840 .973$ & - & Rp3.940.973 \\
\hline
\end{tabular}

Sumber:PT.Gracia Mitra Selaras Pusat Pantai Indah Kapuk Jakarta Utara

Dari tabel 1 di atas, menunjukan bahwa gaji pad tahun 2019 tidak ada kenaikan atau penyesuaian sesuai dengan regulasi pemerintah, selain itu bonus yang diberikan hanya pada tahun 2018 mengalami penururan dan pada tahun terdapat 3 (tiga) store dengan kantor pusat beralamat di Rukan Gold Coast Blok A No. 12-23 Bukit Golf Mediterania Pantai Indah Kapuk Jakarta Utara, dan dua lainnya yang merupakan cabang berada di daerah Muara Karang Jakarta Utara dan BSD Serpong Tangerang.

Motivasi sangat penting dalam meningkatkan kualitas kerja karyawan pada PT. Gracia Mitra Selaras dituntut agar memiliki sumber daya manusia yang berkualitas terbaik yang memiliki motivasi yang tinggi, serta bertanggung jawab terhadap tugas-tugasnya sebagai karyawan. Berdasarkan pra survei yang penulis lakukan pada PT. Gracia Mitra Selaras sudah melakukan motivasi serta tunjangan dengan beberapa bentuk pemberian motivasi seperti familly gathering atau outing ataupun berbagai pelatihan dan training yang sifatnya untuk meningkatkan motivasi dan menambah khazanah ilmu bagi karyawan, namun 6 bulan terakhir ini kinerja karyawan dirasakan menurun

sehingga masalah yang terjadi masih terdapat beberapa gejala seperti menurunya motivasi, gairah dan semangat kerja karyawan pada PT. Gracia Mitra Selaras. Hal ini disebabkan tidak diberikannya imbalan finansial yaitu bonus yang setiap bulan diberikan kepada seluruh karyawan hal ini menyebabkan kinerja karyawan tidak maksimal hal ini bukanlah tanpa alasan yang menimbulkan menurunnya motivasi karyawan pada PT, Gracia Mitra Selaras. 
Tabel 2. Tunjangan Jabatan PT. Graca Mitra Selaras Pusat Pantai Indah Kapuk Jakarta Utara

\begin{tabular}{|c|c|c|c|c|c|c|}
\hline \multirow{2}{*}{ No } & \multirow{2}{*}{ Jabatan } & \multicolumn{5}{|c|}{ Tunjangan Jabatan } \\
\cline { 3 - 7 } & & $\mathbf{2 0 1 7}$ & $\mathbf{2 0 1 8}$ & Peresentase & $\mathbf{2 0 1 9}$ & Peresentase \\
\hline 1 & Area Manager & Rp10.000.000 & Rp9.500.000 & Turun 5\% & Rp9.310.000 & Turun 3\% \\
\hline 2 & Stote Manager & Rp7.500.000 & Rp7.125.000 & Turun 5\% & Rp6.982.500 & Turun 3\% \\
\hline 3 & SMD & $R p 3.000 .000$ & $R p 2.850 .000$ & Turun 5\% & Rp2.793.000 & Turun 3\% \\
\hline 4 & Supervisor & $R p 1.500 .000$ & Rp1.425.000 & Turun 5\% & Rp1.396.500 & Turun 3\% \\
\hline 5 & Leader & $R p ~ 500.000$ & $R p ~ 475.000$ & Turun 5\% & Rp 465.000 & Turun 3\% \\
\hline
\end{tabular}

Sumber:PT.Gracia Mitra Selaras Pusat Pantai Indah Kapuk Jakarta Utara

Dari tabel 2 di atas, menunjukan bahwa tunjangan jabatan yang diberikan dari tahun 2018-2019 mengalami penurunan yaitu pada tahun 2018 mengalami penurunan sebesar $5 \%$, dan pada tahun 2019 mengalami penurunan sebesar 3\%, jika hal ini terjadi secara terus menerus tentu akan membuat karyawan semakin kecewa dan kinerja semakin memburuk.

Motivasi yang baik yaitu mengemukakan bahwa niat untuk mencapai tujuan merupakan sumber motivasi kerja yang utama. Artinya, tujuan memberi tau seorang karyawan apa yang harus dilakukan dan berapa banyak usaha yang harus dikeluarkan. Ini yang menjadi bahan pertimbangan perusahaan untuk memberikan apresiasi atau penghargaan kepada karyawan.

Berdasarkan survey pendahuluan, peneliti mendapatkan informasi mengenai disiplin dan motivasi terhadap karyawannya melalui Kepala Bagian Sumber Daya Manusia (SDM) yang menyebutkan bahwa karyawan PT. Gracia Mitra Selaras Pusat Pantai Indah Kapuk Jakata Utara masih terdapat karyawan yang tidak disiplin yaitu datang tidak tepat waktu. Untuk menciptakan kinerja pegawai yang efektif dan efisien tidak mudah, tidak hannya menciptakan disiplin kerja yang tinggi saja tetapi faktor motivasi juga mempengaruhi.

Suatu organisasi atau perusahaan di tuntut untuk memiliki pandangan sikap disiplin untuk meningkatkan kinerja pegawai, disiplin merupakan perwujudan sikap atau mental dan perilaku suatu kelompok atau individu ditinjau dari aspek kepatuhan dan ketaatan terhadap ketentuan peraturan dan hukum yang berlaku dalam suatu kehidupan berbangsa dan bernegara, yang disimpulkan bahwa disiplin adalah dimana seseorang dapat mematuhi setiap peraturan serta hukum atau sanksi pada suatu organisasi atau perusahaan.Contoh sederhana dalam hal ini aalah, jika seseorang karyawan sering datang terlambat maka secara otomatis hal tersebut akan merugikan organisasi dimana dia bekerja kerugian yang nyata diantaranya :

1. Berkurangnya jam kerja bagi yang bersangkutan sehingga kemungkinan besar target akan merosot atau tidak tercapai.

2. Pengarung negatif bagi karyawn lainnya terutama jika perilaku indisipliner tersebut dibiarkan berlarutlarut.

3. Munculnya sikap malas dan tak acuh jika sikap pembiaran oleh atasan yang bersangktan berkelanjutan.

Disiplin menjadi tolak ukur untuk manajer atau pemimpin secara keseluruhan dapat dilaksanakan dengan baik atau tidak. Disiplin juga salah satu bentuk dari pengendalian diri karyawan dan pelaksanaan yang teratur dalam menunjukan tingkat kesungguhan kerja karyawan pada suatu perusahaan atau pun organisasi, dimana karyawan yang tidak mematuhi peraturan yang telah di tetapkan oleh perusahaan maka karyawan akan mendapatkan sanksi, Oleh karena itu tindakan disiplin ini tidak bisa diterapkan secara sembarangan, sehingga memerlukan pertimbangan yang sangat bijak. 
Tabel 3. Absensi Karyawan PT. Gracia Mitra Selaras Pantai Indah Kapuk Jakarta Utara Periode 2017-2019

\begin{tabular}{|c|c|c|c|c|c|c|c|c|c|c|c|c|c|c|c|}
\hline \multirow{3}{*}{ Jabatan } & \multicolumn{15}{|c|}{ Data Absensi Periode Tahun 2017-2019 } \\
\hline & \multicolumn{5}{|c|}{ Tahun 2017} & \multicolumn{5}{|c|}{ Tahun 2018} & \multicolumn{5}{|c|}{ Tahun 2019} \\
\hline & $S$ & I & CT & A & DT & $\mathbf{S}$ & I & CT & A & DT & $\mathbf{S}$ & I & CT & A & DT \\
\hline Area Manager & 1 & 3 & 5 & - & - & 5 & 11 & 2 & - & 2 & 7 & 6 & 3 & - & - \\
\hline Store Manager & - & 2 & 4 & - & - & 3 & 6 & 2 & - & 1 & 4 & 6 & 3 & - & \\
\hline SMD & 4 & 1 & 2 & - & 2 & 7 & 9 & 3 & - & 3 & 4 & 12 & 6 & - & 5 \\
\hline Supervisor & 1 & 4 & 5 & - & 2 & 1 & 3 & 2 & - & 1 & 3 & 19 & 12 & - & - \\
\hline Leader & 3 & 5 & 3 & - & - & 2 & 7 & 3 & 1 & 3 & 11 & 7 & 9 & - & 5 \\
\hline Sraff & 9 & 14 & 11 & 11 & 16 & 12 & 14 & 7 & 18 & 12 & 6 & 10 & 16 & 27 & 19 \\
\hline $\begin{array}{l}\text { Jumlah hari } \\
\text { absen }\end{array}$ & 18 & 29 & 30 & 11 & 20 & 30 & 50 & 19 & 19 & 22 & 35 & 60 & 49 & 27 & 29 \\
\hline Score & \multicolumn{5}{|c|}{108} & \multicolumn{5}{|c|}{140} & \multicolumn{5}{|c|}{200} \\
\hline $\begin{array}{l}\text { Jumlah hari } \\
\text { kerja }\end{array}$ & \multicolumn{5}{|c|}{350} & \multicolumn{5}{|c|}{350} & \multicolumn{5}{|c|}{350} \\
\hline Persentase & \multicolumn{5}{|c|}{$30 \%$} & \multicolumn{5}{|c|}{$40 \%$} & \multicolumn{5}{|c|}{$57 \%$} \\
\hline
\end{tabular}

Sumber:PT.Gracia Mitra Selaras Pusat Pantai Indah Kapuk Jakarta Utara

Berdasarkan tabel 3 dapat peneliti jelaskan bahwa, kehadiran karyawan selama periode tahun 2017 sampai dengan tahun 2019. Pada tahun 2017 menunjukan bahwa sebayak 18 karyawan sakit, 29 karyawan izin, 30 karyawan cuti, 11 karyawan, alpha, 20 karyawan datang terlambat. Kemudian pada tahun 2018 menunjukan bahwa sebayak 30 karyawan sakit, 50 karyawan izin, 19 karyawan cuti, 19 karyawan alpha, 22 karyawan datang terlabat. Sedangkan pada tahun 2018 menunjukan bahwa sebayak 35 karyawan sakit, 60 karyawan izin, 49 karyawan cuti, 27 karyawan alpha, 29 karyawan datang terlabat. Tinginya jumlah karyawan tanpa keteranangan dan keterlambatan ini akan berdampak pada beban kerja karyawan lainnya, dimana pekerjaan karyawan yang tidak masuk akan dilimpahkan kepada karyawan lainnya, sedangkan karyawan yang terlambat akan menganggu perkerjaan lannya dimana kordisi dan hubungan kerja menjadi tidak tepat waktu.

Sebagian karyawan juga kurang perduli terhadap barang yang kosong pada rak tidak segera di isi dengan barang baru yang tersedia di gudang toko. Sehingga sebagian besar customer malas bertanya

Tabel 4. Target dan Pencapaian PT. Gracia Mitra Selaras Pusat Pantai Indah Kapuk Jakarta Utara 2017-2019

\begin{tabular}{|c|c|c|c|c|c|}
\hline No. & Tahun & \multicolumn{3}{|c|}{ Periode 2017-2019 } & Keterangan \\
\hline & & Target Penjualan & Pencapaian Penjualan & Persentase (\%) & \\
\hline 1 & 2017 & Rp 78.955 .354 .080 & $\begin{array}{ll}\operatorname{Rp} & 78.937 .220 .720 \\
\end{array}$ & $99 \%$ & Tidak Tercapai \\
\hline
\end{tabular}




\begin{tabular}{|l|l|ll|ll|l|l|}
\hline 2 & 2018 & $\mathrm{Rp}$ & 83.061 .237 .600 & $\mathrm{Rp}$ & 82.010 .620 .312 & $98 \%$ & Tidak Tercapai \\
\hline 3 & 2019 & $\mathrm{Rp}$ & 79.461 .248 .400 & $\mathrm{Rp}$ & 75.937 .220 .720 & $95 \%$ & Tidak Tercapai \\
\hline
\end{tabular}

Sumber:PT.Gracia Mitra Selaras Pusat Pantai Indah Kapuk Jakarta Utara

Berdasarkan data tabel 4 menunjukan maka dengan demikian bahwa kinerja bahwa pada tahun 2017 hingga tahun 2019 pencapaian penjualan mengalami penurunan pada setiap tahunnya. Jika secara terus menerus mengalami penurunan tiap tahunya secara signifikan

karyawan kurang baik.

Berikut adalah data hasil penilaian pada karyawan PT. Gracia Mitra Selaras Pusat Pantai Indah Kapuk Jakarta Utara.

Tabel 5. Penilaian pada karyawan PT. Gracia Mitra Selaras Pusat Pantai Indah Kapuk Jakarta Utara

\begin{tabular}{|c|c|c|c|c|c|}
\hline \multirow{2}{*}{ No } & \multirow{2}{*}{ Komponen Penilaian } & \multicolumn{3}{|c|}{ Tahun } & \multirow[t]{2}{*}{ Keterangan } \\
\hline & & 2017 & 2018 & 2019 & \\
\hline 1 & Kualitas & 70 & 65 & 70 & Sedang \\
\hline 2 & Kuantitas & 65 & 63 & 65 & Sedang \\
\hline 3 & Tanggung Jawab & 69 & 63 & 65 & Sedang \\
\hline 4 & Pelaksanaan Tugas & 68 & 65 & 70 & Sedang \\
\hline \multicolumn{2}{|c|}{ Rata-rata Setiap Tahun } & 68 & 64 & 67,5 & \\
\hline \multicolumn{2}{|c|}{ Rata-rata 3 tahun terakhir } & \multicolumn{3}{|c|}{66,5} & Sedang \\
\hline
\end{tabular}

Berdasarkan tabel 5 menunjukan bahwa pada PT. Gracia Mitra Selaras, dari total 120 karyawan pencapaian kerja berada pada tataran yang masih terkoreksi. Evaluasi yang dilakukan merupakan salah satu upaya untuk mengetahui kemajuan organisasi. Rata-rata secara keseluruhan pada tahun 2017 mencapai nilai 68, pada tahun 2018 mencapai nilai 64, dan pada tahun 2019 mencapai nilai kuantitas mencapai nilai 67,5. Namun dari hasil keseluruhan rata-rata dalam tiga tahun terakhir yaitu tahun 2017-2019 mencapai nilai 66,5 dimana nilai tersebut masih dalam kategori sedang tetapi perlu ditingkatkan kembali untuk mencapai kriteria sangat baik.

\section{TINJAUAN PUSTAKA}

1. Motivasi

Menurut Sedarmayanti (2018:138) motivasi adalah kekuatan yang mendorong seseorang untuk melakukan tindakan atau tidak yang pada hakikatnya ada secara internal dan eksternal posotif maupun negatif untuk mengarahkannya sangat bergantung pada ketangguhan pimpinan. Sutrisno (2017:110) berpendapat motivasi adalah keadaan kejiwaan yang mendorong, mengaktifkan, atau menggerakkan dan motivasi yang mengarahkan dan menyalurkan prilaku, sikap, dan tindak seseorang.

2. Disiplin Kerja

Menurut Singodimedjo (2016:86) disiplin adalah sikap kesediaan dan kerelaan seseorang untuk memenuhi dan menaati norma-norma peraturan yang berlaku disekitarnya. Disiplin karyawan yang baik akan mempercepat tujuan perusahaan, sedangkan disiplin yang merosot akan menjadi penghalang dan memperlambat pencapaian tujuan perusahaan.

3. Kinerja Karyawan

Menurut Mangkunegara (2017:67) kinerja adalah hasil kerja secara kualitas yang dicapai oleh seseorang pegawai dalam melaksanakan tugasnya sesuai dengan tanggung jawab yang diberikan kepadanya. Kinerja adalah melakukan pekerjaan dan hasil yang dicapai dari pekerjaan tersebut, menurut wibowo (2017:7).

\section{METODE}

Penelitian ini bersifat kuantitatif asosiatif. Populasi pada penelitian ini adalah pada karyawan tetap yang berjumlah 120 orang karyawan yang bekerja di PT. Gracia Mitra Selaras Pantai Indah Kapuk. Jumlah populasi dalm penelitian ini adalah seluruh karywan yang 
bekerja di perusahaan PT. Gracia Mitra Selaras Pusat Pantai Indah KapukJakarta Utara. Dalam penelitian ini penulis mempersempit populasi yaitu jumlah karyawan sebanyak 120 karyawan dengan menghitung ukuran sampel yang dilakukan dengan menggunakan tektin Slovin menurut Sugiyono (2017:87). Adapun penelitian ini menggunakan rumus Slovin karena dalam penarikan sampel, jumlahnya harus preventive agar hasil penelitian dapat direalisasikan dan penghitungannya pun tidak memerlukan tabel jumlah sampel, namun dapat dilakukan dengan rumus dan perhitungan sederhana sebagai berikut:

$$
\begin{gathered}
\mathrm{n}=\frac{N}{1+N(e)^{2}} \\
=\frac{120}{1+0,3}=\frac{120}{1,3}=92
\end{gathered}
$$

Berdasarkan perhitungan diatas sampel yang menjadi responden sebanyak 92 karyawan dari seluruh total karyawan PT. Gracia Mitra Selaras Pusat Pantai Indah Kapuk Jakarta Utara hal ini dilakukan untuk mempermudah dalam pengolahan data dan untuk hasil pengujian yang lebih baik.

\section{HASIL DAN PEMBAHASAN}

\section{Uji Regresi Linear Berganda}

Tabel 6. Uji Regresi Motivasi dan Disiplin Kerja Terhadap Kinerja

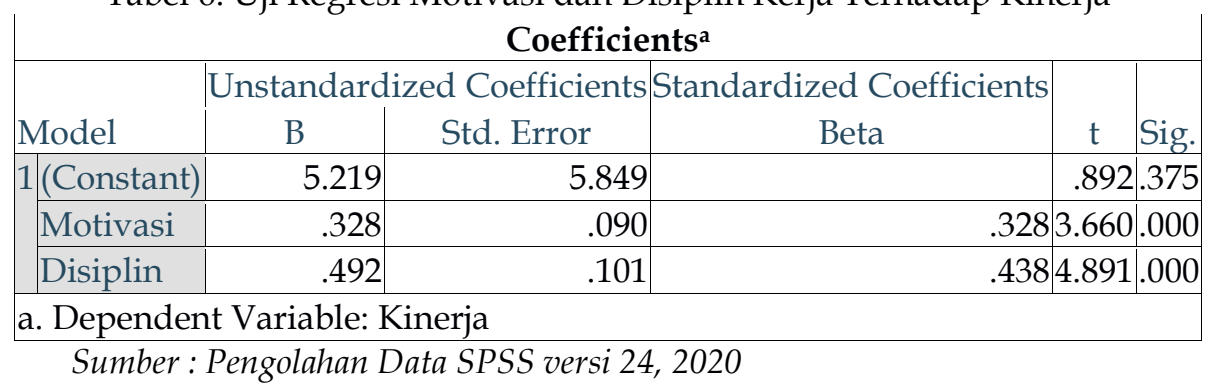

Berdasarkan tabel 6 di atas, maka berikut: persamaan resgresi linear berganda sebagai $\quad Y=5,129+0,328(X 1)+0,492$ (X2)

\begin{tabular}{|c|c|c|c|c|c|}
\hline \multicolumn{6}{|c|}{ Tabel 7. Uji F } \\
\hline \multicolumn{6}{|c|}{ ANOVA $^{a}$} \\
\hline Model & Sum of Squares & df & Mean Square & $\mathrm{F}$ & Sig. \\
\hline 1 Regression & 350.586 & 2 & 175.293 & 17.962 & $.000^{b}$ \\
\hline Residual & 868.577 & 89 & 9.759 & & \\
\hline Total & 1.219 .163 & 91 & & & \\
\hline \multicolumn{6}{|c|}{ a. Dependent Variable: Kinerja } \\
\hline \multicolumn{6}{|c|}{ b. Predictors: (Constant), Motivasi,Disiplin } \\
\hline
\end{tabular}

\section{Uji Hipotesis}

Tabel 7 Uji F menunjukan bahwa nilai $\mathrm{F}$ hitung sebesar 17,962 dengan tingkat (sig) 0,000, maka selanjutnya dicari berapa nilai $\mathrm{F}$ tabel. Untuk melihat $\mathrm{F}$ tabel dalam pengujian hipotesis pada model regresi perlu menentukan derajat bebas atau degree freedom (df) atau dikenal dengan df2 dan juga dalam $F$ tabel disimbolkan dengan N2. Hal ini ditentukan dengan rumus:

$$
\text { Df }=\mathbf{n}-\mathbf{k}-\mathbf{1}
$$

Maka dengan didapatkan df untuk uji t yaitu $\mathrm{df}=\mathrm{n}-\mathrm{k}-1$, maka nilai $\mathrm{F}$ tabel dengan tingkat kepercayaan $5 \%$ atau 0,5 $\mathrm{df}=92-2-1$ adalah 3,10. Berdasarkan hasil outout SPSS di atas kita dapat melihat dimana nilai $\mathrm{F}$ hitung 17,965 > 3,10 dengan tingkat signifikansi $0,000<$ 0,05. Maka Ho di tolak dan Ha diterima yang menyatakan terdapat pengaruh yang signifikan secara simultan (bersama) antara pengaruh motivasi dan disiplin kerja terhadap kinerja karyawan 
pada PT. Gracia Mitra Selaras Pusat Pantai Indah Kapuk Jakarta Utara.

\section{Koefisien Korelasi}

Dari output hasil SPSS 24 diatas dketahui nilai $r$ hitung (Pearson Correlation) : Diketahui nilai $\mathrm{r}$ hitung untuk hubungan Motivasi (X1) dengan Kinerja (Y) adalah sebesar 0,310 > r tabel 0,205, maka dapat disimpulkan bahwa ada hubungan atau korelasi antara variabel Motivasi dengan Kinerja. Selanjutnya, diketahui nilai $r$ hitung untuk hubungan Disiplin (X2) dengan Kinerja $(Y)$ adalah sebesar 0,425 > r tabel 0,205, maka disimpulkan bahwa ada hubungan atau korelasi antara variabel Disiplin dengan Kinerja.

Tabel 8. Hasil Uji Koefisien Korelasi

\begin{tabular}{|c|c|c|c|c|}
\hline \multicolumn{5}{|c|}{ Correlations } \\
\hline & & Motivasi & Disiplin & Kinerja \\
\hline \multirow{3}{*}{ Motivasi (X1) } & Pearson Correlation & 1 & -.040 & $.310^{* *}$ \\
\hline & Sig. (2-tailed) & & .703 & .003 \\
\hline & $\mathrm{N}$ & 92 & 92 & 92 \\
\hline \multirow[t]{3}{*}{ Disiplin (X2) } & Pearson Correlation & -.040 & 1 & $.425^{* *}$ \\
\hline & Sig. (2-tailed) & .703 & & .000 \\
\hline & $\mathrm{N}$ & 92 & 92 & 92 \\
\hline \multirow[t]{3}{*}{ Kinerja (Y) } & Pearson Correlation & $.310^{* *}$ & $.425^{* *}$ & 1 \\
\hline & Sig. (2-tailed) & .003 & .000 & \\
\hline & $\mathrm{N}$ & 92 & 92 & 92 \\
\hline \multicolumn{5}{|c|}{ **. Correlation is significant at the 0.01 level (2-tailed). } \\
\hline
\end{tabular}

\section{Koefisien Determinasi}

Untuk mengetahui besar persentase kontribusi antara Motivasi (X1) dan Disiplin (X2) terhadap Kinerja

(Y) Karyawan pada PT Gracia MItra Selaras diukur dengan koefisien determinasi atau koefisien determinasi atau koefisien penentu sebagai berikut: Tabel 9. Uji Determinasi Variabel $X 1$ dan $X 2$ terhadap $Y$

\begin{tabular}{|c|c|c|c|c|}
\hline \multicolumn{5}{|c|}{ Model Summary } \\
\hline Model & $\mathrm{R}$ & $\begin{array}{c}\mathrm{R} \\
\text { Square }\end{array}$ & $\begin{array}{l}\text { Adjusted } \\
\text { R Square }\end{array}$ & $\begin{array}{l}\text { Std. Error of the } \\
\text { Estimate }\end{array}$ \\
\hline 1 & $.496^{\mathrm{a}}$ & .246 & .230 & 2.904 \\
\hline \multicolumn{5}{|c|}{ a. Predictors: (Constant), Total X2, Total X1 } \\
\hline
\end{tabular}

Hasil dari nilai (R Square) sebesar 0,246 . Hal ini menunjukan bahwa sebesar 24,6\% Motivasi (X1) dan Disiplin (X2) memiliki kontribusi pengaruh terhadap KInerja $(Y)$,

\section{PENUTUP}

\section{Kesimpulan}

Berdasarkan hasil penelitian dan analisis data yang dilakukan dalam penelitian ini mengenai pengaruh motivasi dan disiplin kerja terhadap kinerja karyawan pada PT. Gracia Mitra Selaras Pusat Pantai Indah Kapuk Jakarta Utara, maka penulis menyimpulkan sebagai berikut:
1. Hasil penelitian ini menunjukan variabel Motivasi (X1) diperoleh nilai $\mathrm{t}$ tabel sebesar 1,985. Jadi karena nilai thitung > t tabel, yaitu 3,660 > 1,985. Hal tersebut juga diperkuat dengan nilai signifikandi pdengan nilai $\rho$ value < Sig. 0,05 atau probabilitas (signifikan) - 0,000 yaitu berada di bawah 0,05 maka dapat disimpulkan bahwa terdapat pengaruh yang positif.

2. Hasil penelitian ini menunjukan variabel Disiplin (X2) diperoleh nilai $\mathrm{t}$ tabel sebesar 1,985. Jadi karena nilai t hitung $>$ $\mathrm{t}$ tabel, yaitu 4,891 >1,985, dengan nilai probabilitas (signifikansi) $=0,000$ yaitu di bawah 0,05. Dengan demikian $\mathrm{Ho} 2$ 
ditolak dan Ha2 diterima, hal ini dinyatakan bahwa terdapat pengaruh positif dan signifikan secara parsial antara Motivasi dan Disiplin kerja karyawan pada PT. Gracia Mitra Selaras Pusat Pantai Indah Kapuk Jakarta Utara.

3. Motivasi dan Disiplin kerja secara bersama-sama memiliki pengaruh yang positif dan signifikan terhadap kinerja karyawan di PT. Gracia Mitra Selaras Pusat Pantai Indah Kapuk Jakarta Utara. Berdasarkan hasil perhitungan yang telah di dapat Diketahui nilai F hitung sebesar 17,962 nilai tersebut lebih besar dari $F$ tabel 0,310 dengan nilai sig. sebesar 0,000 dan tingkat signifikansi sebesar $5 \%$ atau 0,05 yang berarti bahwa hipotesis dalam penelitian ini $\mathrm{Ha} 3$ diterima.

\section{Saran}

1. Pada variabel Motivasi (X1) PT. Gracia Mitra Selaras Pusat Pantai Indah Kapuk Jakarta Utara indiator gaji untuk dapat ditingkatkan kembali untuk lebih baik lagi perusahaan lebih memperhatikan atas memberian upah Sebaiknya perusahaan tidak mengacu pada upah minimun tetapi upah yang sesuai degan tugas dan tanggung jawab karyawan, melainkan upah yang layak bagi tenaga kerja, agar penerima upah dapat memenuhi kebutuhan hidupnya.

2. Pada variabel Disiplin (X2) karyawan PT. Gracia Mitra Selaras Pusat Pantai Indah Kapuk Jakarta Utara masih harus terus ditingkatkan karena dalam proses kepatuhan terhadap peraturan, karyawan masih ada yang tidak patuh dan taat .Oleh karena itu PT. Gracia Mitra Selaras Pusat Pantai Indah Kapuk Jakarta Utara perlu memberikan sanksi atau teguran kepada para karyawan yang melanggar peraturan tersebut agar mampu mengatasi masalah kepatuhan peraturan tersebut.

3. Diketahui nilai $r$ hitung untuk hubungan Motivasi (X1) dengan Kinerja (Y) adalah sebesar 0,310 > r tabel 0,205, maka dapat disimpulkan bahwa ada hubungan atau korelasi antara variabel Motivasi dengan
Kinerja. Selanjutnya, diketahui nilai $r$ hitung untuk hubungan Disiplin (X2) dengan Kinerja ( $Y$ ) adalah sebesar 0,425 > r tabel 0,205, maka disimpulkan bahwa ada hubungan atau korelasi antara variabel Disiplin dengan Kinerja.

\section{DAFTAR PUSTAKA}

A. Anwar Prabu Mangkunegara. 2016. Manajemen Sumber Daya Manusia Perusahaan. Bandung: PT. Remaja Rosdakarya .

A.Anwar Prabu Mangkunegara. 2017. Manajemen Sumber Daya Manusia Perusahaan. Cetak ke Empat Belas. Bandung: PT. Remaja Rosdakarya .

Andrew E. Sukula. 2017. Personel Administration and Human Resources Management. John \& Sons Inc.

Edy Sutrisno. 2017. Manajemen Sumber Daya Manusia. Pranada Media Group, Jakarta.

Endang Susilowati dan Kemas Vivi Andayani (2021) Pengaruh Lingkungan Kerja dan Disiplin Kerja terhadap Kinerja Pegawai pada Panti Sosial Bina Grahita Belaian Kasih Jakarta Barat

Ghozali. 2016. Aplikasi Analisis Multivariate Dengan Program SPSS. Semarang: Badan Penerbit Universita Dipenogoro.

Hasibuan, 2018. Organizational Behavior: Concepts, Controversies , and Aplocation, 3rd ED., Prentice-Hall, International Ed.

Lewenussa, R., \& Rawi, R. D. P. (2020). Discriminant Study with Classification of Underdeveloped and Developing City Districts in West Papua Province. Ekuilibrium: Jurnal Ilmiah Bidang Ilmu Ekonomi, 15(2), 103117.

Lilis-Suryani, N. (2017). Pengaruh Motivasi Dan Kompetensi Terhadap Kinerja Pegawai Pada Sekretariat Jenderal Dewan Perwakilan Daerah Republik Indonesia. JENIUS (Jurnal Ilmiah Manajemen Sumber Daya Manusia), 1(1). 
Meilawati, D., et al. (2019). Pengaruh Pemberian Insentif Terhadap Kinerja Karyawan Pada Pt Telesindoshop Kota Sorong. Manajemen Dewantara, 3(1), 128-137.

Nurjaya, N., et al (2021). Pengaruh Kompetensi Sumber Daya Manusia Dan Kemampuan Pemanfaatan Teknologi Terhadap Kinerja Aparatur Desa Pada Kantor Kepala Desa Di Kabupaten Gunungkidul, Yogyakarta. JENIUS (Jurnal Ilmiah Manajemen Sumber Daya Manusia), 4(3), 332-346.

Paeno, P. (2018). Pengaruh Motivasi dan Disiplin Terhadap Produktivitas Kerja Karyawan Pada PT. Agra Energi Indonesia. JENIUS (Jurnal Ilmiah Manajemen Sumber Daya Manusia), 1(3).

Pawar, A., Sudan, K., Satini, S., \& Sunarsi, D. (2020). Organizational Servant Leadership. International Journal of Educational Administration, Management, and Leadership, 63-76.

Rawi, R. D. P. (2017). Analisis Hubungan Motivasi Terhadap Kinerja Pegawai (Studi Kasus Pada Kantor Kecamatan Ruing Kabupaten Ngada Ntt). Jurnal Noken: Ilmu-Ilmu Sosial, 2(2), 15-28.

Salim, A. O., \& Rawi, R. D. P. (2020). Pengaruh Jaminan Sosial Tenaga Kerja Terhadap Produktivitas Kerja Karyawan Pada PT Sumber Abadi Indonesia Cabang Kota Sorong Papua Barat. Jurnal Ilmiah Manajemen Emor (Ekonomi Manajemen Orientasi Riset), 4(1), 32-40.

Sardiman, A.M. 2017. Interaksi dan Motivasi Belajar Mengajar .Jakarta: Rajawali Pers.
Serdamayanti. 2018. Manajemen Sumber Daya Manusia. Bandung: Refika Aditama.

Siagian, Sondang P. 2018. Sumber Daya Manajemen Manusia. Jakarta: Bumi Aksara.

Simamora. 2017. Manajemen Sumber Daya Manusia. Yogyakarta: Bagian Penerbitan Sekolah Tinggi Ilmu Ekonomi YKPN.

Singodimedjo, Markum.2017. Manajemen Sumber Daya Manusia. Surabaya : SMMAS.

Sugiyono. 2016. Metode Penelitian Kuantitatif dan R\&D. Bandung: ALFABETA.

Sukarno K. 2018. Dasar-Dasar Manajemen. Jakarta: CV Telaga Bening

Sukmadinata, Nana Syaodih. 2018. Metode Penelitian Pendidikan. Bandung : PT. Ra Rosdakarya.

Sunarsi, D., Wijoyo, H., Prasada, D., \& Andi, D. (2020, September). Pengaruh lingkungan kerja terhadap kinerja karyawan pada pt. Mentari persada di jakarta. In Seminar Nasional Manajemen, Ekonomi, Akuntansi (Vol. 5, No. 1, pp. 117-123).

Wether \& Davis. 2017. A to Z Human Capital Manajemen. Dalam Jimmy L. Goal.Jakarta : Grasindo.

Wibowo. 2017. Manajemen Kinerja. Cetak ke Dua Belas. Depok: PT. Raja Grafindo

Winata, H. (2019). Hubungan Motivasi Terhadap Kinerja Karyawan Pada Bank Pembangunan Daerah Jawa Barat Dan Banten Tbk.(Bank Bjb) Cabang Bsd-Tangerang Selatan. JENIUS (Jurnal Ilmiah Manajemen Sumber Daya Manusia), 2(2), 212-223. 